\title{
Are Asian Principals Capable to Lead-Cases from India, Malaysia and Thailand?
}

\author{
Sailesh Sharma \\ University of Malaya, Malaysia
}

\begin{abstract}
The study examines Malaysian, Indian and Thai teachers' perception of the leadership capacities of their principals. One hundred and seventy seven teachers from Malaysia, one hundred and seventy two teachers from India and one hundred sixty four teachers from Thailand participated in the study. Questionnaire titled 'My Principals' Leadership Capacities' specifically developed for this research by researcher was used to collect data. Findings showed that perception of teachers differed significantly in these three Asian countries. Perception of Thai teachers about leadership capacities of their principal was negative while Malaysian and Indian teachers' perception was positive in all six ISLLC standards.
\end{abstract}

\section{Introduction}

Leadership plays an indispensible role in effectiveness of an educational institution, right from the setting of goals to accomplishment of goals. Various researches have linked the school effectiveness with the leadership. In absence of leadership goal accomplishment and school effectiveness is never guaranteed. In view of Cheng and Townsend [1] for education change and effectiveness, the role of principal is often crucial to their success. The principal is challenged to create the culture of quality that penetrates to the smallest elements, processes and the systems of an institution. It is common experience that under the same set of rules and regulations, with same set of teaching staff and students from similar background, an educational institution degenerates or maintains status quo, or rises to prominence with a change of principal. This is also borne out by large number of research studies on management of change in education, Mukhaopadhyay [2]. In view of developing the good leaders for the schools, Ministry of Education Government of Malaysia through its Educational Leadership Centre and Institute of Principalship Studies University of Malaya [3] and Ministry of
Human Resources \& Development, Government of India through Indian Institute of Management and National University of Educational Planning \& Administration [4] is providing various programmes of Leadership development for school principals.

\section{Literature Review}

Various researchers have tried to interpret school leadership in different manner. Peretomode [5] stated the importance of Leadership in school for accomplishment of school programmes, objectives and attainment of educational goals. Cheng [6] proposed that leadership in educational institutions compose of five major dimensions, namely: structural leadership, human leadership, political leadership, cultural leadership and educational leadership. These five dimensions describe the role and functions of school leader. However the functions of principal put a variety of demands and challenges for the principal Mestry and Grobler [7]. In an attempt to explain the requirements of a competent principal, Cranston [8] explained the skills and capacities which principals are expected to possess which are as follows

1. Aspects of strategic leadership - people, school, educational.

2. Aspects of strategic management - facilities, budgeting, staffing, accountability.

3. Leading, visioning, cultural change

4. Knowledge of state, national and international educational developments.

5. Knowledge of wider organization and development issues beyond education section.

6. Capacity to manage and developments (educational and otherwise).

7. Capacity to make, manage and lead through uncertainty.

The Interstate School Leaders Licensure Consortium (ISLLC) provides the six standards for the school leaders [9]. 


\section{Standard 1}

A school administrator is an educational leader who promotes the success of all students by facilitating the development, articulation, implementation, and stewardship of a vision of learning that is shared and supported by the school community.

Standard 2

A school administrator is an educational leader who promotes the success of all students by advocating, nurturing, and sustaining a school culture and instructional program conducive to student learning and staff professional growth.

\section{Standard 3}

A school administrator is an educational leader who promotes the success of all students by ensuring management of the organization, operations, and resources for a safe, efficient, and effective learning environment.

\section{Standard 4}

A school administrator is an educational leader who promotes the success of all students by collaborating with families and community members, responding to diverse community interests and needs, and mobilizing community resources.

\section{Standard 5}

A school administrator is an educational leader who promotes the success of all students by acting with integrity, fairness, and in an ethical manner.

\section{Standard 6}

A school administrator is an educational leader who promotes the success of all students by understanding, responding to, and influencing the larger political, social, economic, legal, and cultural context.

Principals' competencies can be measured from various dimensions; from the perceptions of students, teachers, parents, communities and their employers. For instance, Scotti Jr. and William [10] agreed that teachers' perceptions of their principals' leadership is one of the many variables, which affect a school's productivity. Teachers' perception of principals' leadership behavior is also positively related to teachers' morale Hunter-Boykin and Evans [11]. Luo [12] further contended that perceptions about principals as leaders by their teachers indicate an important dimension to evaluate the leaders capacities. According to him, understanding how teachers perceive their principals leadership capacities has a great significance and providing evidence for improvement of school leadership. Research has also demonstrated those teachers' perceptions of their principals' capabilities and their working conditions will determine the organizational climate and culture of the school. Such perceptions will also impact on the performance of the school.In a study in America, Hunter-Boykin and Evans [11] found that majority of the principals were rated as ineffective by their teachers. This reflects that there is a big discrepancy between what the principals' are and how they are perceived by the teachers. And in Hong Kong, the images of the principal in the mind of pre-service primary teachers were found to be negative (Lee, Walker and Bodycott, [13]). A study by Luo and Najjar [14], investigated Chinese principal leadership capacities as perceived by master teachers. Unlike in many developed countries where studies on principals' competencies are available in multitude, such studies are still at its low in Malaysia, India and in Thailand. Keeping in mind the importance of role of the principal as a leader within the secondary school system, it is imperative to examine the leadership capacities of school principals. This is particularly so because of the fact that schools in these countries serve for the large section of national students. Most studies in these countries have focused on leadership styles, rather than leadership competencies. The study therefore intends to fill this gap by examining the perception of teachers of the leadership capacities of their principals. It also intends to examine the output of various programmes organized by government of these countries in developing leadership capacities of the school principals.

\section{Objective of the Study}

The objective of this study is to examine how the senior teachers in Malaysia, India and Thailand perceive the leadership capacities of their principals.

\section{Methodology}

\subsection{Sample}

The samples of the study were made up of the one hundred seventy seven senior teachers from Malaysia, one hundred seventy two senior teachers from India and one hundred sixty four senior teachers from Thailand. All the samples have a minimum teaching qualification of a first degree and working with their schools for over five years in Malaysia and Thailand, while in India are senior teachers with Master degree as it is mandatory for senior teachers to have Master degree.

\subsection{Instrument}

The instrument used for the study was self developed questionnaire My Principals' Leadership Capacities to measure the leadership capacities of 
Principals. The questionnaire included items that were developed from the statements of ISLLC standards. It comprises 27 items covered by six dimensions of school vision, instructional leadership, organizational management, collaboration, moral perspectives and larger context politics. The questionnaire used 6 point likert scale with 0 being the lowest ,supported by statement never descriptive about my principal indicating no capacity, followed by 1 rarely descriptive about my principal indicating having little capacity,2 sometimes descriptive about my principal indicating having somewhat capacity,3 often descriptive about my principal indicating having moderate capacity, 4 usually descriptive about my principal indicating having strong capacity and 5 always descriptive about my principal indicating having excellent capacity.

The reliability of instrument was carried thirty five teachers in Malaysia, thirty seven teachers in Thailand and fifty four teachers in India Their response was analyzed with the aid of split half method and it provided reliability co-efficient $0.87,0.83$ and 0.86 respectively. The instrument is therefore reliable to measure the leadership capacities school principals in these countries. Data collected for the study were analyzed calculating Mean and Standard Deviation.

\subsection{Data Analysis}

Data were analyzed using SPSS 17.0 software. Mean scores and standard deviations were calculated for each of the 27 to determine the teachers' perceptions of their principals' leadership capacities.

Table 1. Mean \& Standard Deviation for Six Dimensions of Leadership Capacities

\begin{tabular}{|c|c|c|c|c|c|c|}
\hline \multirow[t]{2}{*}{ Dimensions } & \multicolumn{2}{|c|}{$\begin{array}{l}\text { Malaysian } \\
\text { Teachers }\end{array}$} & \multicolumn{2}{|c|}{$\begin{array}{l}\text { Thai } \\
\text { Teachers }\end{array}$} & \multicolumn{2}{|c|}{$\begin{array}{l}\text { Indian } \\
\text { Teachers }\end{array}$} \\
\hline & $\mathrm{M}$ & SD & $\mathrm{M}$ & $\mathrm{SD}$ & $M$ & SD \\
\hline School Vision & 3.81 & 1.04 & 2.40 & .73 & 4.18 & .925 \\
\hline Inst Lead* & 3.51 & .84 & 2.33 & .92 & 4.14 & .83 \\
\hline Org.Mgm** & 3.81 & .72 & 2.15 & .53 & 4.41 & .75 \\
\hline Collaboration & 3.49 & .80 & 2.76 & .82 & 3.82 & .81 \\
\hline $\begin{array}{l}\text { Moral } \\
\text { Perspectives }\end{array}$ & 3.71 & .70 & 2.83 & .74 & 3.77 & .73 \\
\hline $\mathrm{LCP} * * *$ & 3.62 & .86 & 2.62 & .57 & 4.12 & .83 \\
\hline
\end{tabular}

*Instructional Leadership

** Organizational Management

*** Larger Context Politics

From table 1 it's clear that all Thai teachers have perceived their principals to be having somewhat capacities in all six dimensions of leadership capacities, while Malaysian teachers have perceived their principals to be having moderate capacities in all six dimensions. In contrary to Thai and Malaysian principals, Indian principals are perceived to be having strong capacities in four dimensions i.e. School Vision, Instructional Leadership, Oraganisational leadership and larger context politics, while having moderate capacities in collaboration and Moral Perspectives. No principal from three countries is perceived to be having excellent capacity.

Table 2. ANOVA for Six Dimensions of Leadership Capacities

\begin{tabular}{|l|c|c|}
\hline Dimensions & F Value & Significance \\
\hline School Vision & $\mathbf{4 5 . 6 2 2}$ & $\mathbf{. 0 0 0}$ \\
\hline Inst Lead* & $\mathbf{3 8 . 8 0 4}$ & $\mathbf{. 0 0 0}$ \\
\hline Org.Mgm** & $\mathbf{4 4 . 1 6 0}$ & $\mathbf{. 0 0 0}$ \\
\hline Collaboration & $\mathbf{2 8 . 5 2 6}$ & $\mathbf{. 0 0 0}$ \\
\hline $\begin{array}{l}\text { Moral } \\
\text { Perspectives }\end{array}$ & $\mathbf{4 0 . 3 3 1}$ & $\mathbf{. 0 0 0}$ \\
\hline $\begin{array}{l}\text { LCP*** } \\
\text { *Instructional Leadership } \\
\text { ** Organizational Management } \\
\text { *** Larger Context Politics }\end{array}$
\end{tabular}

From Table 2 it is evident that $\mathrm{F}$ value for all the six dimensions of leadership capacity is significant enough to express the differences in perception of Leadership capacities of principals in these three Asian countries. This clearly indicates that teachers have perceived their principal's leadership capacities differently in these three Asian countries. However it can be commended that Indian principals have better leadership capacities than Malaysian and Thai principals.

\section{Conclusion}

The results of the study revealed that the teachers' perception of their principals' leadership capacities were negative in case of Thai principals while positive in case of Malaysian and Indian principals. The findings from Malaysian and Indian perspectives seemed to be in contrast with the result of a study conducted by Hunter-Boykin and Evans [11] in America that $67 \%$ of the principals were rated as ineffective principals by their teachers while Thai perspective have shown alignment with these studies. This study has somewhat contradicted the Researches 
carried out in Hongkong by Lee, Walker, and Bodycott, [13], and in China by Luo and Najjar, [14] in case of Malaysian and Indian principals. The results contribute to the large body of school leadership literature by adding the Malaysian, Thai and Indian perspectives. It provides evidence to understand the situations of Asian principal leadership capacities compared to the American educational leadership program standards. These results surprise many educators in Malaysia and India; they provide valuable information based on the empirical study for both educators and government who are exerting more and more efforts in the improvement of education in these countries.

\section{References}

[1] Cheng, Y.C and Townsend, T., (2000). Educational change and development in the Asian Pacific region: trends and issues, In T. Townsend and Y.C. Cheng (Eds). Educational change and development in the Asia-Pacific region: Challenges for the future, Rotterdam: Swets and Zeitlinger.

[2] Mukhopadyay, M., (2001), Total Quality Management in Education, New Delhi: National Institute of Educational Planning \& Administration.

[3] Institute of Principalship Studies, University of Malaya, www.ipk.um.edu.my.

[4] Strategic Management \& Leadership for Principals of CBSE schools. news.icbse.com/strategic-managementleadership-principals-cbse-schools-489-india.

[5] Peretomode, V.F., (1991). Educational Administration: Applied Concepts and Theoretical Perspectives, Lagos: Joja Educational Research and Publishers Ltd.

[6] Cheng, Y.C., (1994). Principal's leadership as a critical indicator of school performance: Evidence from multilevels of primary schools, School Effectiveness and School Improvement: An International Journal of Research, Policy and Practice, 5(3), pp: 299-317.

[7] Mestry, R. and Grobler, B.R., (2004). The training and development of principals to manage schools effectively using the competence approach, International Studies in Educational Administration, 32(3), pp: 2-19.

[8] Cranston, N.C., (2002). School based management, leaders and leadership: change and challenges for principals, International Studies in Educational Administration, 30(1), pp: 2-12.

[9] The Interstate School Leaders Licensure Consortium (ISLLC), www.coe.fgcu.edu/faculty/valesky/ISLLC Standards.htm
[10] Scotti, Jr. and William, H., (1987). Analysis of organisational incongruity using teachers' perceptions of the principals' leadership behavior, Education, 108(1), pp: 27-33.

[11] Hunter-Boykin, H. S., and Evans, V. 1995. The relationship between high school principals' leadership and teachers' morale. Journal of Instructional Psychology, 22(2), 152-163.

[12] Luo, M., (2004). Geographic disparities of Chinese School Principals' leadership capacities: A perspective of teachers' perceptions, International Studies in Educational Administration, 32(3), pp: 20-33.

[13] Lee, J.C.K, Walker, A. and Bodycott, P., (2000). Preservice primary teachers' perceptions about principals in Hong Kong: Implications for teachers and principal education, Asia-Pacific Journal of Teacher Education, 28(1), pp: 53-67.

[14] Luo, M. and Najjar, L., (2007). The Chinese Principal Leadership capacities as perceived by Master Teachers, Academic Leadership: the Online Journal, vol. 4, Issue 3. 